DOI 10.37882/2500-3682.2021.05.26

\title{
ИЗУЧЕНИЕ ИЗМЕНЕНИЙ МОТИВАЦИОННОГО КОМПОНЕНТА ПСИХОЛОГИЧЕСКОЙ ГОТОВНОСТИ К ПРОФЕССИОНАЛЬНОЙ ДЕЯТЕЛЬНОСТИ У СТУДЕНТОВ-ЮРИСТОВ В УСЛОВИЯХ СМЕНЫ ФОРМ ОБУЧЕНИЯ
}

\section{EXPLORING THE CHANGES \\ OF THE MOTIVATIONAL COMPONENT \\ PSYCHOLOGICAL READINESS \\ TO PROFESSIONAL ACTIVITIES LAW \\ STUDENTSIN THE FACE OF CHANGING FORMS OF LEARNING}

\section{A. Sokolova \\ E. Korablina \\ Yu. Tarasova}

Summary: The article provides the results of a theoretical justification for the role of the motivational component in the structure of psychological readiness for professional activities in law students, as well as an analysis of empirical data of changes in the structure of the motivational component and its dynamics over the past three years in the conditions of changing the form of training.

Keywords: professional development, psychological readiness, motivation, motivation structure, dynamics of motives, students-lawyers, change of form of education, cross-section.
Д анное исследование посвящено изучению мотивационного компонента психологической готовности обучающихся студентов юридического факульета, в условиях перехода от традиционного формата обучения на инновационный дистанционный формат.

Психологическая готовность к профессиональной деятельности студентов выступает одним из условий, определяющих дальнейшие инварианты профессионального самоопределения и профессиональной судьбы будущих специалистов. В сложную многокомпонентную структуру профессиональной готовности составной частью входит мотивационный компонент (потребностно-мотивационный, побудительный), в свою очередь состоящий из элементов.

Цель исследования - изучить динамику изменения мотивов и возможную смену ведущих мотивов при переходе на инновационный формат обучения.

В исследовании использовался различный комплекс методов: наблюдение, беседа, анкетирование, стандар-
Соколова Алена Ивановна

Аспирант, Российский государственный университет правосудия Северо-Западный Филиал alena_sokolova@mail.ru

Кораблина Елена Павловна

Д.псх.н., профессор, Российский государственный университет правосудия Северо-Западный Филиал

Тарасова Юлия Николаевна

К.nсх.н., дочент, Российский государственный университет правосудия Северо-Западный Филиал

Аннотация: В статье приводятся результаты теоретического обоснования роли мотивационного компонента В структуре психологической готовности к профессиональной деятельности у студентов юристов, а также анализ эмпирических данных изменения структуры мотивационного компонента и его динамики за последние три года в условиях смены формы обучения.

Ключевые слова: профессиональное становление, психологическая готовность, мотивация, структура мотивов, динамика мотивов, студенты-юристы, изменение формы обучения, поперечные срезы.

тизованные самоотчеты, тест-опросники. В качестве основной диагностической процедуры использовалась методика диагностики учебной мотивации студентов (А.А. Реан и В.А. Якунин, модификация Н.Ц. Бадмаевой) [6].

Теоретическую базу составили исследования И.Б. Гладких [2], рассматривающий мотивацию в дистанционном образовании, что также актуально для данного исследования; Н.Ю. Максимова [5], описывающая важность тренинга (активной формы обучения, предполагающую получение опыта в межличностном взаимодействии) в психолого-педагогическом обеспечении мотивационной готовности студентов; Е.И. Пилюгина, О.В. Бережнова [7], рассматривающие фактор профессиональной мотивации в повышении эффективности образования; И.П. Попова [8], оценивающая в своей работе профессию юриста на современном рынке труда и делающая вывод об универсальности юридического образования как площадки для развития в различных областях труда; Е.М. Рожков [9], представивший обзор исследований отечественных и зарубежных ученых в 
области мотивации; Е.Ю. Рубанова [10], исследующая психологическую готовность как важный фактор обеспечения конкурентноспособности выпускника; Е.Р. Сагеева, О.А. Аникеенок [11], диагностирующие мотивационную готовность по методике, основанной на «теории ожиданий» В. Врума; Г.Н. Травинова [13], выделившая из методики «Изучение факторов привлекательности профессии» факторы, влияющие на отношение к профессии юриста; Е.Н. Шарова [14], исследующая профессиональное самоопределение в условиях трансформации современного общества, и др. Работы вышеназванных авторов посвящены психологической и мотивационной готовности (в т.ч. и студентов-юристов) и лежат в смежной к данному исследованию области и др.

Имеющиеся в литературе данные показывают, что существует тесная связь между успешностью профессионала в любом виде деятельности и качеством сформированной психологической готовности [12, с.597].

Психологическая готовность будущего профессионала проявляется через мотивационно-целевой компонент, в свою очередь находящейся в тесной положительной корреляционной зависимости с практической деятельностью. На степень психологической готовности влияет как овладение необходимыми знаниями, умениями и навыками, необходимыми для осуществления профессиональной деятельности, так и индивидуальные особенности личности. Даже должным образом организованный учебный процесс не гарантирует профессионального развития будущего специалиста как субъекта труда, если не будет встречной активности самих обучающихся.

Состояние мотивационного компонента в структуре психологической готовности обучающихся студентов выступает показателем степени осмысленности и осознанности ими в достижении профессиональных целей, коррелирует с успешностью в будущей деятельности в качестве специалиста, активизирует когнитивные, эмоционально-оценочные и регулятивные компоненты самосознания личности [5, с. 40]), влияющие на переход теоретических знаний в практические умения и навыки.

Не существует единого представления о соотношении понятий «мотив» и «мотивация». Мотив рассматривается учеными как внутренний побудитель к удовлетворению потребности; как цель или как намерение; как потребность и т.д. [3, с. 252]. Мотивация как дефиниция имеет разные трактовки: система факторов, определяющих поведение; система мотивов; побуждение, стимулирующее деятельность и определяющее направление этой деятельности; совокупность процессов, отвечающих за деятельность и побуждение к ней и т.д. Из данных формулировок выделяются два подхода к определению мотивации: мотивация как совокупность мотивов и мо- тивация как средство реализации уже существующих мотивов. Под мотивацией учебной деятельности имеются в виду «все факторы, обусловливающие проявление учебной активности: потребности, цели, установки, чувство долга, интересы и т.п.» [3, с. 253].

При выборе профессии важную роль играет первичные представления оптанта о будущей профессиональной деятельности, на чем изначально выстраивается мотивационно-целевая структура. Установлено, что оптанты, как правило, ориентируются на гуманитарную сферу наук и относительную доступность поступления на юридический факультет [8, с. 47]. При этом оптанты также обращают внимание на общественную престижность данной профессии и на возможность достижения определенного статуса в обществе. Ранее проведенное исследование, направленное на выяснение факторов привлекательности профессии юриста (методика В.А. Ядова) [13, с. 89], показало, что 63,7\% оптантов ориентировались на полезность образования юриста в целом, 23,3\% опирались на личностные интересы и индивидуальные особенности личности, 8,7\% пошли в профессию для помощи другим людям и достижения социальной значимости, 4,3\% ориентировались на социально экспансированный образ юриста как общественного «героя» (к примеру, в сериалах, СМИ, кино и т.д.).

Профессиональная направленность будущего специалиста включает оценку оптантом важности и привлекательности профессиональной деятельности, будущей заработанной платы, возможность личностной самореализации, карьерные перспективы, соответствие профессии личностным качествам и т.д., что оценивается более осмысленно по мере обучения и освоения специальности в вузе. Как отмечает Г.Н. Травинова, на последних курсах студент юридического факультета определяет перспективы профессионального самосовершенствования, социального признания и уважения, но негативное отношение вызывает переутомление, ненормированный рабочий день, а также контакты с различными людьми (потерпевшие, свидетели и т.д.) [13, с. 90].

Мотивация как психологический фактор играет огромную роль и в дистанционном образовании. Высокая мотивация к получению знаний и овладению профессии является основой для саморегуляции и осуществления дистанционного обучения в целом, где можно выделить целый ряд трудностей [2, с. 58]:

- возможный низкий уровень внутренней мотивации;

- ожидание контроля преподавателя и в силу этого слабая саморегуляция и самоорганизация;

- новый, непривычный формат обучения;

- отсутствие контакта с другими студентами, разобщенность в группе и т.д. 
По данным наблюдения установлено, что студенты юридического факультета, работая с большим объемом когнитивно сложной информации и документов, могут быстро потерять интерес к изучаемым предметам. При низком уровне мотивации и неорганизованности формируется отчуждение от профессии и в дальнейшем отмечается недостаточная психологическая готовность к осуществлению профессиональной деятельности (в результате чего студент-выпускник не работает по профессии) [2, с. 61].

В данном исследовании сделана попытка изучения динамики и соотношение мотивов:

1. социальных (осознание общественной значимости получения образования, стремление занять определенное положение в обществе, взаимодействие с людьми);

2. учебно-познавательных (получение новых знаний, в том числе и самостоятельно);

3. престижа (стремление к достижению определенного уровня в какой-либо деятельности);

4. избегания неудачи (стремление избежать порицания);

5. коммуникативных (взаимодействие с другими людьми, познание людей);

6. творческой самореализации (в профессиональном труде, нахождение личностного смысла в профессии, творческого отношения к профессии);

7. профессиональных (стремления обеспечить продуктивность и успешность будущей профессиональной деятельности, установка на трудовую деятельность).

Гипотеза исследования: смена формы обучения выступает фактором, оказывающим влияние на изменение структуры и выраженности мотивов у обучающихся студентов. В подгруппах студентов (с высоким и низким уровнем сформированности мотивации) выраженность и динамика мотивов будет отличаться. У многих студентов смена традиционной формы обучения на очно-дистанционную сначала понижает мотивационную готовность, однако, затем происходит компенсация структуры мотивов во всех подгруппах в условиях дистанционного обучения.

Выборку исследования составили студенты юридического факультета в количестве 686 студентов первых курсов.

Организационный метод исследования - метод поперечных срезов.

Исследование длилось три года и охватило три группы студентов, в зависимости от формы и года обучения:

- очная форма (2018 г.) - студенты первого курса (стандарт традиционного формата), 181 чел.;

- очно-дистанционная форма (2019 г.) - студенты первого курса, перешедшие на очно-дистанционный формат после прохождения полугода очного стандартного обучения и месяца самоизоляции, 145 чел.;

- дистанционная форма (2020 г.) - студенты первого курса, поступившие и обучающиеся исключительно в дистанционном формате, без опыта обучения в очном (стандартном) формате обучения в ВУЗе, 360 чел.

При формировании дизайна выборки использовалась стратегия «выделение и сравнение полярных групп». По каждому году обучения были выделены подгруппы с высоким и низким уровнем сформированности изучаемых мотивов, численность экспериментальных групп составила 35 человек.

Статистическая обработка проводилась в программе IBMSPSS Statistics v.22.

Результаты исследования приведены в таблице 1 и графике 1, представляющей собой поперечные срезы

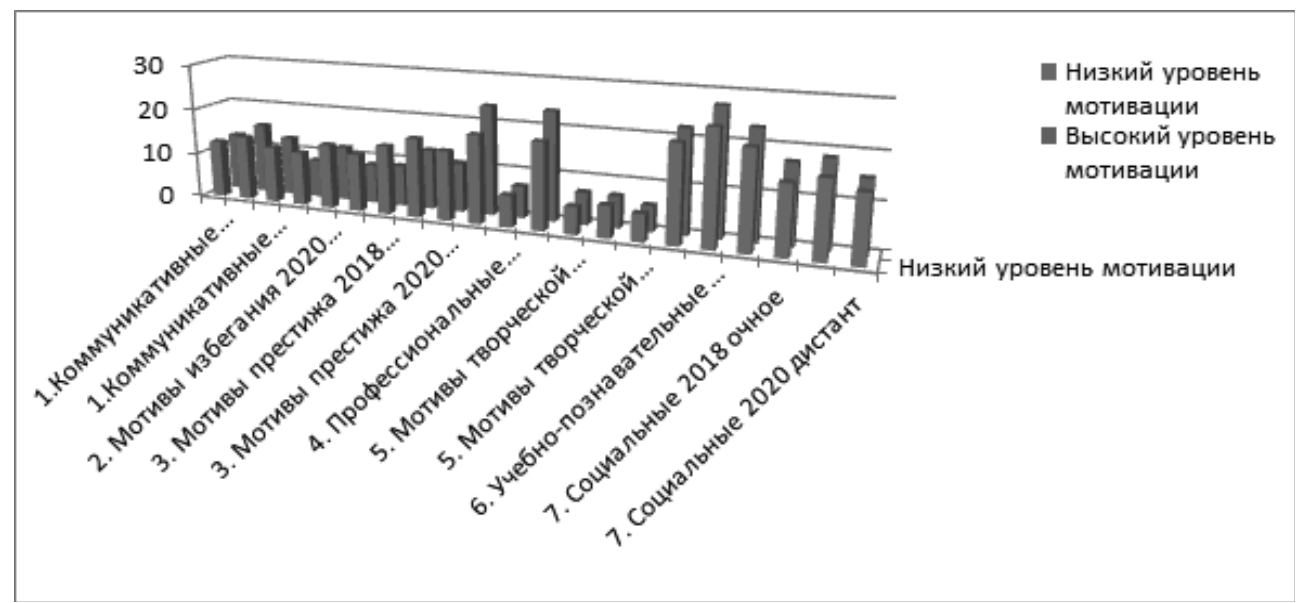

График 1. Параметры выраженности мотивов учебной деятельности студентов-юристов в условиях смены форм обучения 
Таблица 1.

Параметры выраженности мотивов учебной деятельности студентов-юристов

в условиях смены форм обученияв подгруппах с разным уровнем мотивации (средние значения, в баллах)

\begin{tabular}{|c|c|c|c|c|c|c|}
\hline \multirow{2}{*}{ Форма обучения } & \multicolumn{2}{|c|}{2018 г. } & \multicolumn{2}{|c|}{2019 г. } & \multicolumn{2}{|c|}{2020 г. } \\
\hline & \multicolumn{2}{|c|}{ Очная } & \multicolumn{2}{|c|}{ Очно-дистанционная } & \multicolumn{2}{|c|}{ Дистанционная } \\
\hline Группы & \multicolumn{2}{|c|}{ подгруппы } & \multicolumn{2}{|c|}{ подгруппы } & \multicolumn{2}{|c|}{ подгруппы } \\
\hline \multirow[t]{2}{*}{ Мотивы учебной деятельности } & $\begin{array}{c}\text { высокий } \\
\text { уровень } \\
\text { мотивации } \\
\end{array}$ & $\begin{array}{c}\text { низкий } \\
\text { уровень } \\
\text { мотивации } \\
\end{array}$ & $\begin{array}{c}\text { высокий } \\
\text { уровень } \\
\text { мотивации } \\
\end{array}$ & $\begin{array}{c}\text { низкий } \\
\text { уровень } \\
\text { мотивации } \\
\end{array}$ & $\begin{array}{c}\text { высокий } \\
\text { уровень } \\
\text { мотивации }\end{array}$ & $\begin{array}{c}\text { низкий } \\
\text { уровень } \\
\text { мотивации } \\
\end{array}$ \\
\hline & $\bar{M}$ & $\bar{M}$ & $\overline{\mathrm{M}}$ & $\overline{\mathrm{M}}$ & $\overline{\mathrm{M}}$ & $\overline{\mathrm{M}}$ \\
\hline 1.Коммуникативные мотивы & 19.08 & 11.5 & 19.53 & 11.88 & 19.26 & 13.03 \\
\hline 2. Мотивы избегания & 17.79 & 7.577 & 19.47 & 9.18 & 19.62 & 8.629 \\
\hline 3. Мотивы престижа & 22.76 & 8.115 & 23.8 & 10.06 & 23.74 & 10.71 \\
\hline 4. Профессиональные мотивы & 29.08 & 21.77 & 9.533 & 5.375 & 29.6 & 24 \\
\hline 5. Мотивы творческой самореализации & 9 & 6.423 & 9.533 & 5.375 & 9.238 & 5.686 \\
\hline 6. Учебно-познавательные мотивы & 31.88 & 20.46 & 34 & 21.19 & 33.38 & 23.77 \\
\hline 7. Социальные мотивы & 22.64 & 15.77 & 22.93 & 14.44 & 22.79 & 15.49 \\
\hline Итого: & 152 & 91.62 & 159.1 & 90.88 & 157.6 & 101.3 \\
\hline
\end{tabular}

Таблица 2.

Соотношение мотивов в подгруппе студентов с высоким уровнем сформированности мотивов в 2018-2020 гг. (средние значения в баллах и \%)

\begin{tabular}{|c|c|c|c|c|c|c|}
\hline \multirow{2}{*}{ Форма обучения } & \multicolumn{2}{|c|}{2018 г. } & \multicolumn{2}{|c|}{2019 г. } & \multicolumn{2}{|c|}{2020 г. } \\
\hline & \multicolumn{2}{|c|}{ Очная } & \multicolumn{2}{|c|}{ Очно-дистанционная } & \multicolumn{2}{|c|}{ Дистанционная } \\
\hline Группы & \multicolumn{2}{|c|}{ подгруппы } & \multicolumn{2}{|c|}{ подгруппы } & \multicolumn{2}{|c|}{ подгруппы } \\
\hline \multirow{2}{*}{ Мотивы учебной деятельности } & \multicolumn{2}{|c|}{$\begin{array}{c}\text { высокий } \\
\text { уровень мотивации }\end{array}$} & \multicolumn{2}{|c|}{$\begin{array}{c}\text { высокий } \\
\text { уровень мотивации }\end{array}$} & \multicolumn{2}{|c|}{$\begin{array}{c}\text { высокий } \\
\text { уровень мотивации }\end{array}$} \\
\hline & M & $\%$ & M & $\%$ & M & $\%$ \\
\hline 1.Коммуникативные мотивы & 19.08 & 12.53 & 19.53 & 14.07 & 19.26 & 12.22 \\
\hline 2. Мотивы избегания & 17.79 & 11.69 & 19.47 & 14.03 & 19.62 & 12.45 \\
\hline 3. Мотивы престижа & 22.76 & 14.95 & 23.8 & 17.15 & 23.74 & 15.06 \\
\hline 4. Профессиональные мотивы & 29.08 & 19.1 & 9.533 & 6.86 & 29.6 & 18.78 \\
\hline 5. Мотивы творческой самореализации & 9 & 5.91 & 9.533 & 6.86 & 9.238 & 5.86 \\
\hline 6. Учебно-познавательные мотивы & 31.88 & 20.94 & 34 & 24.5 & 33.38 & 21.18 \\
\hline 7. Социальные мотивы & 22.64 & 14.87 & 22.93 & 16.52 & 22.79 & 14.46 \\
\hline Иmого: & 152 & 100 & 159.1 & 100 & 157.6 & 100 \\
\hline
\end{tabular}

исследования по каждой из 7-и шкал опросника:

У студентов-юристов очной формы обучения (срез 2018 г.), в подгруппе с высоким уровнем сформированности мотивов обучения (см. таблица 2, рисунок 1) изначально выявлена следующая представленность мотивов: наибольшие долю в структуре занимают учебно-познавательные мотивы (20,94 \%) и профессиональные мотивы (19,1 \%); наименьшую долю - занимают мотивы коммуникативные (12.53\%), мотивы избегания (11. 69 \%) и творческой самореализации - (5.91\%) (см. таблица № 2, рисунок 1).
Отмечается изменение в структуре мотивов и их динамике по данным поперечных срезов за три года (2018-2020 гг.), а именно устойчивый рост всех изучаемых мотивов (кроме профессиональных мотивов) в условиях очно-дистанционной формы обучения (срез 2019 г.), и сохранение достигнутых показателей при дистанционной форме обучения (срез 2020 г.). Доля профессиональных мотивов показывает резкий спад к 2019 г. от 19\% до 6.86 \% (в 2.76 раза). Затем, к 2020 г. структурная представленность профессиональных мотивов снова восстанавливается, до 18.78 \%, т.е. практически до прежнего уровня. 


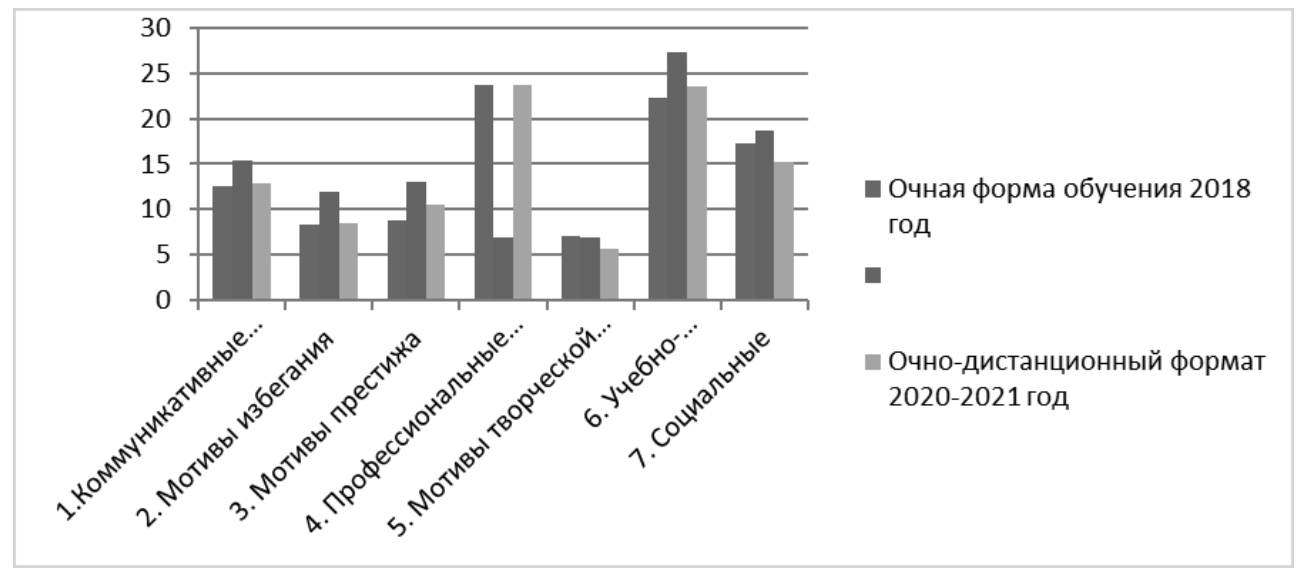

Рис. 1. Динамика мотивов в подгруппе с высоким уровнем сформированности мотивов (в баллах) в 2018-2020 гг.

В диагностическом срезе за 2018 год самые высокие значения (в баллах) отмечены среди учебно-познавательных (31.88) и профессиональных мотивов (29.08), наименьшие значения среди мотивов престижа (22.76), избегания (7.57), и творческой самореализации (6.42).

В срезе за 2019 год самые высокие значения (в баллах) отмечены среди учебно-познавательных (34) и мотивов престижа (23.8), наименьшие значения отмечены среди профессиональных мотивов (9.53), творческой самореализации (9.53).

В срезе за 2020 год самые высокие значения (в баллах) отмечены среди - учебно-познавательных (33.38) и профессиональных мотивов (29.6), наименьшие значения отмечены только среди мотивов творческой самореализации (9.23).

Наибольшая выраженность учебно-познавательных мотивов в структуре общего комплекса мотивов у студентов обусловлена интересом к знаниям, к обретению новых умений и навыков. Эта группа мотивов имеет саму высокую выраженность в условиях очно-дистанционного формата (2019 год).

Студенты, которые изначально обучались в новом формате, не воспринимают такую форму обучения как непривычное явление, совмещая положительные факторы очно-дистанционного формата (обучение в индивидуальном темпе, гибкость, доступность из любого места, удобство, самостоятельная организация свободного времени и времени учебы) с мотивацией к получению диплома и освоению профессии. Такие студенты более устойчивы к новым условиям, но при прохождении производственной практики будет испытывать определенные трудности, так как профессия юриста предполагает высокий уровень сформированной коммуникации.

Второй группой мотивов по приоритетности выступают профессиональные мотивы. Как указывалось выше, отмечается отрицательная динамика по показате- лю профессиональных мотивов (за 2019 г.) Таким образом, снижается психологическая готовность к будущему труду, представление об успешности в будущей профессиональной деятельности, не формируется установка на трудовую деятельность.

2. У студентов-юристов очной формы обучения в подгруппе с низким уровнем сформированности мотивов (см. Таблича 3, рисунок 2) обучения (срез 2018 г.) наибольшая доля в структуре отмечена у профессиональных мотивов (23.76 \%) и учебно-познавательных мотивов (22.33\%). Наименьшие процентные доли - отмечены среди мотивов престижа (8.850\%), избегания (8.27\%) и творческой самореализации (7.01\%).

В структуре мотивов и их динамике от 2018 к 2019 году отмечается рост значений и выраженное изменение структуры мотивов, в частности, наибольшие процентные доли приходятся на мотивы: коммуникативные, избегания, престижа, учебно-познавательные, социальные. Мотивы творческой самореализации показали минимальное снижение. Доля профессиональных мотивов показывает резкий спад от 23.76 \% до 6.93\%, и восстановление структурной представленности при дистанционной форме обучения (срез 2020 г.).

В 2020 г. представленность профессиональных мотивов снова восстанавливается до $23.69 \%$, т.е. практически до уровня 2018 г.

Доли мотивов коммуникативных, избегания, престижа, социальных, учебно-познавательных снова снижаются в 2020 г., но превышают уровни 2018г. но Мотивы творческой самореализации показали устойчивое снижение и наименьшую процентную долю по всем трем годам наблюдений (2018 - 7.01\%, 2019 - 6.93\%, 2020 - 5.61\%).

В диагностическом срезе за 2018 год самые высокие значения (в баллах) отмечены среди учебно-познавательных (20.46) и профессиональных мотивов (21.77), наименьшие значения среди мотивов престижа (8.11), 
Таблица 3.

Соотношение мотивов в подгруппе студентов с низким уровнем сформированности мотивов в 2018-2020 гг. (средние значения в баллах и \%)

\begin{tabular}{|c|c|c|c|c|c|c|}
\hline \multirow{2}{*}{ Форма обучения } & \multicolumn{2}{|c|}{2018 г. } & \multicolumn{2}{|c|}{2019 г. } & \multicolumn{2}{|c|}{2020 г. } \\
\hline & \multicolumn{2}{|c|}{ Очная } & \multicolumn{2}{|c|}{ Очно-дистанционная } & \multicolumn{2}{|c|}{ Дистанционная } \\
\hline Группы & \multicolumn{2}{|c|}{ подгруппы } & \multicolumn{2}{|c|}{ подгруппы } & \multicolumn{2}{|c|}{ подгруппы } \\
\hline \multirow{2}{*}{ Мотивы учебной деятельности } & \multicolumn{2}{|c|}{$\begin{array}{c}\text { низкий } \\
\text { уровень мотивов }\end{array}$} & \multicolumn{2}{|c|}{$\begin{array}{c}\text { низкий } \\
\text { уровень мотивов }\end{array}$} & \multicolumn{2}{|c|}{$\begin{array}{c}\text { низкий } \\
\text { уровень мотивов }\end{array}$} \\
\hline & $\bar{M}$ & $\%$ & $\bar{M}$ & $\%$ & $\bar{M}$ & $\%$ \\
\hline 1.Коммуникативные мотивы & 11.5 & 12.55 & 11.88 & 15.33 & 13.03 & 12.86 \\
\hline 2. Мотивы избегания & 7.577 & 8.27 & 9.18 & 11.85 & 8.629 & 8.51 \\
\hline 3. Мотивы престижа & 8.115 & 8.85 & 10.06 & 12.93 & 10.71 & 10.57 \\
\hline 4. Профессиональные мотивы & 21.77 & 23.78 & 5.375 & 6.93 & 24 & 23.69 \\
\hline 5. Мотивы творческой самореализации & 6.423 & 7.01 & 5.375 & 6.93 & 5.686 & 5.61 \\
\hline 6. Учебно-познавательные мотивы & 20.46 & 22.23 & 21.19 & 27.34 & 23.77 & 23.46 \\
\hline 7. Социальные мотивы & 15.77 & 17.21 & 14.44 & 18.63 & 15.49 & 15.29 \\
\hline Итого: & 91.62 & 100 & 90.88 & 100 & 101.3 & 100 \\
\hline
\end{tabular}

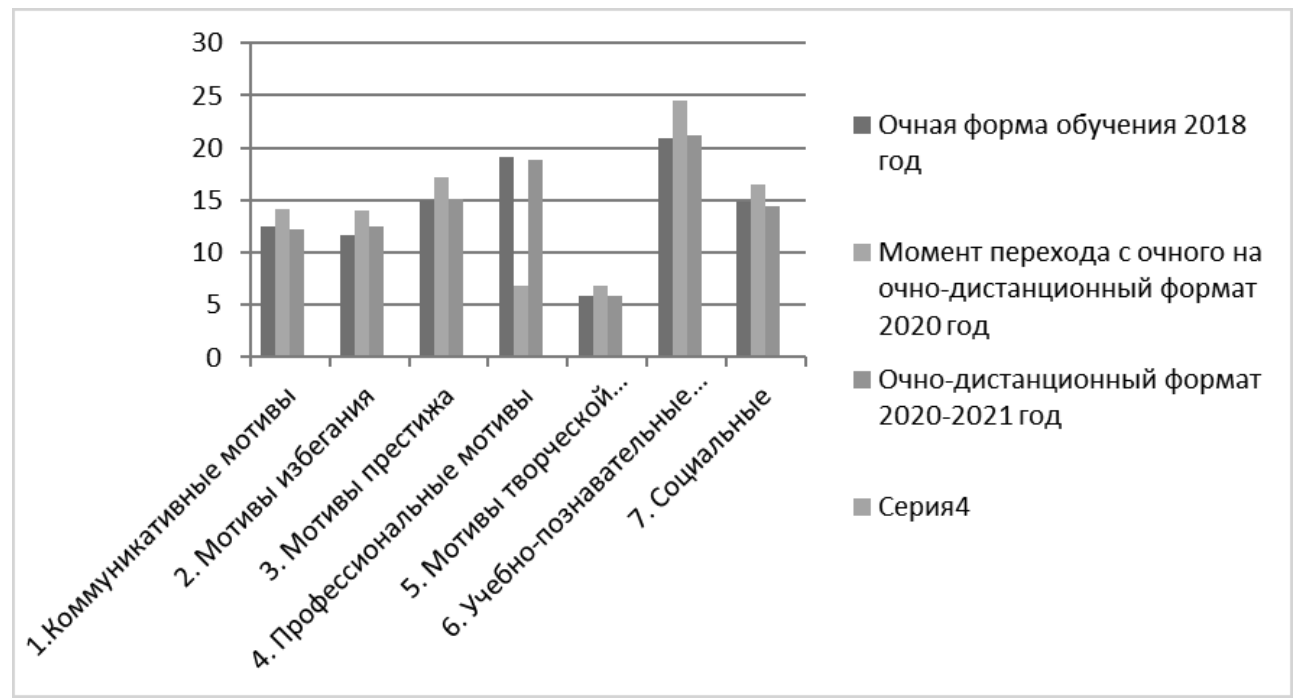

Рис. 2. Динамика мотивов в подгруппе с низким уровнем сформированности мотивов (в баллах) в 20180-2020 гг.

избегания (7.57), и творческой самореализации (6.42).

В срезе за 2019 год самые высокие значения (в баллах) отмечены среди только среди учебно-познавательных (21.19), наименьшие значения отмечены среди профессиональных мотивов (5.37) и творческой самореализации (5.37).

В срезе за 2020 год самые высокие значения (в баллах) отмечены среди - учебно-познавательных (23.77) и профессиональных мотивов (24), наименьшие значения отмечены среди мотивов творческой самореализации (5.68) и мотивов избегания (8.62).

Результат однофакторного дисперсионного анализа (непараметрические методы Фридмана и Пейджа) позволяет принять гипотезу о различии трех форм обучения по влиянию на мотивационную компоненту психологической готовности студентов (на уровне значимости $\mathrm{p}<0,016)$ в подгруппе с высоким уровнем сформированности мотивов, и отсутствии такого влияния в подгруппе с низким уровнем сформированности мотивов.

\section{Выводы}

Смена форм обучения изменяет структуру и соотношение мотивов мотивационной компоненты психологической готовности к профессиональной деятельности у студентов юристов. Смена традиционной формы обучения на очно-дистанционную, в целом, незначительно по- 
нижает мотивационную готовность в подгруппе студентов с низким уровнем сформированности мотивов, и, наоборот, повышает мотивационную готовность в подгруппе с высоким уровнем сформированности мотивов.

В подгруппе студентов с высоким уровнем сформированности мотивов в наибольшей степени структурные изменения затрагивают мотивы профессиональные (при переходе на очно-дистанционный и дистанционный формат). Отмечается компенсация снижения профессиональных мотивов ростом всех других мотивов у обучающихся студентов.
В подгруппе студентов с низким уровнем сформированности мотивов структурные изменения затрагивают также мотивы профессиональные. При переходе на очно-дистанционный формат в наибольшей степени снижаются мотивы профессиональные, и в меньшей степени мотивы творческой самореализации. Отмечается компенсация снижение профессиональных мотивов и мотивов творческой самореализации ростом всех других мотивов.

Таким образом, выдвинутая исследовательская гипотеза подтвердилась в полном объеме.

\section{ЛИТЕРАТУРА}

1. Бадмаева, Н.Ц. Влияние мотивационного фактора на развитие умственных способностей / Н.Ц. Бадмаева. - Улан-Удэ: Изд-во ВСГТУ, 2005. - 203 с.

2. Гладких, И.Б. Мотивация в дистанционном образовании (модель Келлера применимо к студентам с ОВЗ) / И.Б. Гладких // Экономика и управление в XXI веке: тенденции развития. - 2015. - № 25. - С. 58-62.

3. Ильин, Е.П. Мотивация и мотивы / Е.П. Ильин. - СПб: Питер, 2011. - 508 с.

4. Кораблина, Е.П., Пашкин, С.Б. Е.П. Лисовская, Н.Б. Психологическая готовность к профессиональной деятельности у представителей правоохранительных органов Российской Федерации. Текст научной статьи по специальности «Психологические науки» - 2020. - // 0бразовательный вестник «Сознание» ISSN Печатный: Электронный: 2226-7417/ № 6 (22)

5. Максимова, Н.Ю. Психолого-педагогическое обеспечение мотивационной готовности студентов к профессиональной деятельности / Н.Ю. Максимова // Вестник Нижегород. ун-та им. Н.И. Лобачевского. - 2014. - № 1(2). - С. 37-41.

6. Методика для диагностики учебной мотивации студентов (А.А. Реан и В.А. Якунин, модификация Н.Ц. Бадмаевой) / в кн.: Бадмаева, Н.Ц. Влияние мотивационного фактора на развитие умственных способностей / Н.Ц. Бадмаева. - Улан-Удэ: Изд-во ВСГТУ, 2005. - С.151-154.

7. Пилюгина, Е.И. Социально-психологические особенности профессиональной мотивации студентов вуза / Е.И. Пилюгина, 0.В. Бережнова // Современная психология: матер. междунар. науч. конф. (г. Пермь, июнь 2012 г.). - Пермь: Меркурий, 2012. - С. 87-89.

8. Попова, И.П. Невостребованная «Востребованная профессия» в карьерах выпускников-юристов / И.П. Попова // Высшее образование в России. - 2014. - № 1. - C. 45-54.

9. Рожков, Е.М. Мотивация достижения успеха и избегания неудач в работах отечественных и зарубежных ученых / Е.М. Рожков // Современная наука. 2014. - № 3. - С. 44-46.

10. Рубанова, Е.Ю. Психологическая готовность выпускников ВУЗа к профессиональной деятельности / Е.Ю. Рубанова // Ученые заметки ТОГУ. - 2011. - Т. 2; № 1. - C. 53-62.

11. Сагеева, Е.Р. Мотивационная готовность студентов к будущей профессиональной деятельности и проблемы ее изучения / Е.Р. Сагеева, 0.А. Аникеенок // КПЖ. - 2011. - № 3. - С. 78-83.

12. Сластенин В.А. Психология и педагогика /Сластенин В.А. Каширина В.П.//М.: Издательство Юрайт - 2013. - С.593-601.

13. Травинова, Г.Н. К вопросу о динамике факторов привлекательности профессии юриста у студентов вуза / Г.Н. Травинова // МНК0. - 2020. - № 1(80). C. 89-91.

14. Шарова, Е.Н. Профессиональное самоопределение молодежи в условиях социокультурной трансформации российского общества: на примере Мурманской области: автореф. дис. ... канд. соц. наук: 22.00.04 / Е.Н. Шарова. - Архангельск: Сев. (Арктич.) федер. ун-т, 2012. - 25 с. 